\title{
Triple Negative Breast Cancer: A Unique Type of Breast Cancer
}

\section{Ankur Sood*}

Amity Institute of Pharmacy, Amity University, Noida, Uttar Pradesh, India

Keywords: Breast cancer; Triple negative breast cancer; Estrogen; Hormone receptor

\section{Introduction}

Breast cancer is just not a single localize disease but it can show metastasis to the lymph nodes and other distant organ. There are different types of breast cancer. It can even be called a family of diseases which may transfer from one generation to another, altering the disease pattern as a genetic one. All breast cancers initially harbours in different tissues of the breast. Therefore, all the breast cancers apparently seem to be similar, but actually differ in causes and region of causes. The type of breast cancer affects prognosis (outcome) and treatment options [1].

\section{Types of breast cancer}

Breast cancer is divided into two broad categories: non-invasive and invasive.

Non-invasive (in situ) breast cancer: This type of cancer is defined by the cancerous cells localized in one particular portion of breast and do not follow any metastasis.

Invasive (infiltrating) breast cancer: In this particular case, cancerous cells show metastasis and spread to other parts of the body through the bloodstream and lymph nodes. Breast cancer can also be classified based on where in the breast the disease started (e.g., milk ducts, lobules), how the disease grows, and other factors [2].

\section{Triple Negative Breast Cancer (TNBCs)}

The definition of breast cancer has evolved, with triple-negative breast cancer (TNBC) defined as ER negative, $\mathrm{PR}$ negative and lacking over expression of HER2; luminal-A cancers are defined as ER positive and histologically low grade; luminal-B cancers are also mostly ER positive but may express levels of hormone receptor and are often high grade; HER2-positive cancers show amplification and high expression of the HER2 gene [3]. Approximately $75 \%$ of TNBCs express basal markers and, consequently, the triple-negative sub-type is frequently, and erroneously, taken as a surrogate marker for the basal-like sub-type [4,5]. Triple-negative tumours account for $10-20 \%$ of invasive breast cancers and this sub-type carries a poorer prognosis than the luminal tumours [6-8].

\section{Epidemiology of TNBC}

Perou et al. [9] were the first to describe the various molecular subtypes or molecular profiles of breast cancers. They described four subtypes based on cDNA micro-arrays, including a basal-like sub-type of breast cancer, and noted that most triple-negative tumours clustered in the basal-like sub-type [9]. Since then, multiple studies of gene expression profiling have advanced the understanding of the molecular diagnosis of breast cancer, providing the background for oncologists to use the triple-negative phenotype to describe the basal-like molecular sub-type [10-13]. Of the global breast cancer burden, it has been estimated that $\sim 170000$ are TNBC and are often, but not always, basallike breast cancer [14-16]; another study has estimated that $\sim 75 \%$ are basal-like.
Using the population-based California Cancer Registry data, Bauer et al. [17] identified women diagnosed with TNBC between 1999 and 2003 to investigate potential differences between TNBC compared with other breast cancers in relation to age, race/ethnicity, and socio economic status, stage at diagnosis, tumour grade and relative survival. A total of 6370 women were identified as having TNBC and were compared with the 44704 women with other breast cancers.

Stead et al. [18] identified women with invasive breast cancer diagnosed between 1998 and 2006, with data available on tumour grade, stage, ER, PR and HER2 status, and patient age, body mass index (BMI) and self-identified racial/ethnic group. They recruited 415 patients who were racially and ethnically diverse; $47 \%$ were obese and $72 \%$ of tumours were ER positive and/or PR positive, $20 \%$ were triple negative and $13 \%$ were HER2 positive.

\section{Epidemiology of TNBC in India}

Breast cancer is the most common cancer in India. For example, in 2012, it is estimated that approximately 145,000 new patients were diagnosed with breast cancer in India, and nearly 70,000 women died of the disease [7]. Age-standardized 5-year breast cancer survival for Indian women diagnosed with breast cancer is $60 \%$ compared with $>80 \%$ in Western countries. Whereas breast cancer incidence seems to be increasing in the country, epidemiology of the disease is inadequately studied. Prevalence of TNBC in India is reported to be higher than that observed in Western populations; however, there is considerable variation in prevalence rates reported by studies from the region. It is important to obtain a reliable summary estimate of the prevalence of TNBC in India to address the growing burden of breast cancer in the country [19].

\section{Symptoms of TNBC}

In general, TNBC do not differ from other breast cancers but it has some unique features:

\section{Receptor status}

Tests that detect receptors level for estrogens, progesterone and HER2 will be negative. Hormonal therapy only worked when only progesterone or estrogens receptor level are comparatively lesser.

\section{Cell type}

Triple-negative breast cancer resembles the basal cells lining the

*Corresponding author: Ankur Sood, Amity Institute of Pharmacy, Amity University, Noida, Uttar Pradesh 201303, India, Tel: 01202445252; E-mail: ankursood05@gmail.com

Received: December 12, 2016; Accepted: January 23, 2017; Published: January 30, 2017

Citation: Sood A (2017) Triple Negative Breast Cancer: A Unique Type of Breast Cancer. Reconstructive Surgery and Anaplastology 6: 164. doi: 10.4172/2161. 1173.1000164

Copyright: () 2017 Sood A. This is an open-access article distributed under the terms of the Creative Commons Attribution License, which permits unrestricted use, distribution, and reproduction in any medium, provided the original author and source are credited. 
breast ducts. The cells may also be of higher grade, which means they may have tendency to become cancerous cell.

\section{Triple negative cancer is unique}

TNBC is not likely to be found on a mammogram than some other types of breast cancer. Compared to other types, it tends to grow faster. It can be treated, but it may recur early and spread to other parts of the body. The reason behind this is lack of target specific treatment [20].

\section{TNBC Risk Factors}

\section{General risk factors}

Age: Women under age 40-50 are more likely to get triple-negative breast cancer than women over age 60 . In current scenario, younger women age between 23 and 30 also have triple negative breast cancer.

Race: It is more common among African, American and Hispanic women than Asian and non-Hispanic white women.

\section{Genetics}

BRCA1 mutation: BRCA1 and BRCA2 are genes that help in repair damaged DNA. Mutations in BRCA1 and BRCA2 can cause cancer and can be inherited from one generation to another generation within family members. Women with the $B R C A 1$ gene mutation have a higher risk of developing TNBC [21].

\section{Currently Approved Therapies and Treatment Strategies}

There is currently no preferred standard chemotherapy for previously treated patients with TNBC, as previous randomised studies in the metastatic setting have not addressed the predictive values of the molecular subtypes of breast cancers. Treatment is therefore selected (as for other subtypes) from a number of current recommended agents that are approved in the general breast cancer population. Conventional treatments for relapsed patients are limited, particularly, because standard chemotherapeutic regimens containing anthracyclines and taxanes have usually already been given in the adjuvant and neoadjuvant settings.

Anthracyclines and taxanes have been suggested as rechallenge regimens in patients with 6-12 months of disease-free survival following completion of adjuvant chemotherapy and recurrence. There are few data on the use of anthracycline- and taxane-containing rechallenge regimens as first- or second-line therapy for metastatic breast cancer, and there is therefore a lack of reliable evidence documenting their efficacy [22].

The major cause of metastatic treatment failure is multidrug resistance to standard therapies, which can be either primary (preceding drug exposure) or acquired resistance (induced by treatment) [23,24]. Patients with progression or resistance may be given non-crossresistant agents such as capecitabine, gemcitabine, vinorelbine or albumin-bound paclitaxel, and combination regimens with these agents have demonstrated efficacy in studies in patients with anthracyclinepretreated advanced breast cancer [24,25]. Superior survival has been demonstrated with capecitabine plus docetaxel combination therapy compared with docetaxel alone in anthracycline-pretreated patients with advanced breast cancer [26], and until the recent approval of ixabepilone, capecitabine was the only additional agent that was US Food and Drug Administration (FDA)-approved following failure of anthracycline/taxane therapy [27]. The use of multidrug regimens in the treatment of patients with metastatic breast cancer is controversial, particularly when first-line trials of combination regimens have not always addressed the questions directly relevant to daily clinical practice.
The 2009 European School of Oncology Metastatic Breast Cancer Task Force (6th European Breast Cancer Conference) recommended sequential monotherapy for advanced breast cancer, and patientand disease-related factors to be used in determining which patients would benefit from combination regimens, who remain poorly defined [28]. Other consensus groups have arrived at a recommendation to administer polychemotherapy for aggressive disease with associated risks to inner organ function [29]. Therefore, given the aggressive nature of TNBC and the need for tumour shrinkage in most cases, the authors would recommend a multidrug regimen rather than a singledrug regimen for this subtype.

Platinum-based regimens have attracted some attention as potential TNBC therapies, and their use has been supported by the strong association of TNBC tumours with germline mutations in the $B R C A 1$ gene, with $10 \%$ of TNBC tumours having $B R C A 1$ mutation (90\% of BRCA1-mutated tumours are TNBC, and $80-90 \%$ of BRCA1associated breast cancers display a basal-like phenotype) [30,31].

\section{Efficacy of Recently Approved Therapies}

Eribulin has recently been European Medicines Agency (EMA) approved for advanced or metastatic breast cancer in patients who have progressed after at least two chemotherapeutic regimens for advanced disease and who received prior anthracycline and taxane regimens where suitable.

Eribulin was most effective in hormone receptor-negative patients who had a $34 \%$ decreased risk of death compared with TPC chemotherapy, and in TNBC patients, who had a $29 \%$ risk reduction, whereas it was least effective in patients who received eribulin without a treatment history that included capecitabine [32].

Ixabepilone is an epothilone antimicrotubule agent, which was FDA approved in 2007 for locally advanced or metastatic breast cancer in combination with capecitabine after failure of anthracycline/taxane therapy.

Patients treated with ixabepilone plus capecitabine demonstrated a $25 \%$ reduction in the estimated risk of disease progression $(\mathrm{HR}=0.75$, 95\% CI 0.64-0.88) compared with patients who received capecitabine only. The ORR of patients was also greater for the ixabepilone-treated group (35\% vs. $14 \%$ for capecitabine). However, grade $3 / 4$ treatmentrelated adverse events were more frequent in the ixabepilone treatment group than in those receiving capecitabine only, with a greater rate of neuropathy $(21 \%$ vs. $0 \%)$, fatigue $(9 \%$ vs. $3 \%)$ and neutropenia $(68 \%$ vs. $11 \%)[33]$.

The use of anti-angiogenic therapies for TNBC is supported by the highly proliferative nature of TNBC and the importance of vascular endothelial growth factor (VEGF) in the microvascular proliferation of this disease. The anti-VEGF monoclonal antibody bevacizumab has shown benefit in some TNBC subgroups if combined with taxanes and other agents [34-36].

The anti-VEGFR tyrosine kinase inhibitors sunitinib and sorafenib have shown some activity in breast cancer trials with significant TNBC populations, with a $15 \%$ response rate reported for sunitinib in a phase II trial [37]; however, neither agent is currently approved for the treatment of breast cancer. The EGFR-directed monoclonal antibody cetuximab is FDA and EMA approved for the treatment of colorectal and head and neck cancer.

\section{Reference}

1. Abeloff MD, Wolff AC, Weber BL (2008) Cancer of the breast (4th edn). Elsevier, Philadelphia. 
Citation: Sood A (2017) Triple Negative Breast Cancer: A Unique Type of Breast Cancer. Reconstructive Surgery and Anaplastology 6: 164. doi: 10.4172/2161-1173.1000164

Page 3 of 3

2. http://www.cancer.org/cancer/breastcancer/detailedguide/breast-cancerbreast-cancer-types

3. Sotiriou C, Puszati L (2009) Gene expression signature in breast cancer. N Engl J Med 360: 790-800

4. Bertucci F, Finetti P, Cervera N, Esterni B, Hermitte F et al. (2008) How basal are triple-negative breast cancers? Int J Cancer 123: 236-240.

5. Bidard FC, Conforti R, Boulet T (2007) Does triple-negative phenotype accurately identify basal-like tumour? An immunohistochemical analysis based on 143 'triple-negative' breast cancers. Ann Oncol 18: 1285-1286.

6. Vona-Davis L, Rose DP, Hazard H, Howard-McNatt M, Adkins F (2008) Triplenegative breast cancer and obesity in a rural Appalachian population. Cancer Epidemiol Biomarkers Prev 17: 3319-3324.

7. Carey LA, Dees EC, Sawyer L, Gatti L, Moore DT, et al. (2007) The triple negative paradox: Primary tumor chemosensitivity of breast cancer subtypes. Clin Cancer Res 13: 2329-2334

8. Cheang MC, Voduc D, Bajdik C, Leung S, McKinney S, et al. (2008) Basal-like breast cancer defined by five biomarkers has superior prognostic value than triple-negative phenotype. Clin Cancer Res 14: 1368-1376.

9. Perou CM, Sørlie T, Eisen MB, Rijn VD, Jeffrey SS, et al. (2000) Molecular portraits of human breast tumours. Nature 406: 747-752.

10. Sorlie T, Tibshirani R, Parker J, Hastie T, Marron JS, et al. (2003) Repeated observation of breast tumor subtypes in independent gene expression data sets. Proc Natl Acad Sci USA 100: 8418-8423.

11. Sørlie T, Perou CM, Fan C, Geisler S, Aas T, et al. (2006) Gene expression profiles do not consistently predict the clinical treatment response in locally advanced breast cancer. Mol Cancer Ther 5: 2914-2918.

12. Sørlie T, Perou CM, Tibshirani R, Aas T, Geisler S, et al. (2001) Gene expression patterns of breast carcinomas distinguishes tumor subclasses with clinical implications. Proc Natl Acad Sci USA 98: 10869-10874.

13. Sørlie T, Wang Y, Xiao C, Johnsen H, Naume B, et al. (2006) Distinct molecular mechanisms underlying clinically relevant subtypes of breast cancer: gene expression analyses across three different platforms. BMC Genomics 7: 127.

14. Foulkes WD, Smith IE, Reis-Filho JS (2010) Triple-negative breast cancer. N Engl J Med 363: 1938-1948.

15. Anders CK, Carey LA (2009) Biology, metastatic patterns, and treatment of patients with triple-negative breast cancer. Clin Breast Cancer 9: S73-S81.

16. Rakha EA, Ellis IO (2009) Triple-negative/basal-like breast cancer: a review. Pathology 41: 40-47.

17. Bauer KR, Brown M, Cress RD, Parise CA, Caggiano V, et al. (2007) Descriptive analysis of estrogen receptor (ER)-negative, progesterone receptor (PR)-negative, and HER2-negative invasive breast cancer, the so-called triplenegative phenotype: a population-based study from the California Cancer Registry. Cancer 109: 1721-1728.

18. Stead LA, Lash TL, Sobieraj JE, Chi DD, Westrup JL, et al. (2009) Triplenegative breast cancers are increased in black women regardless of age or body mass index. Breast Cancer Res 11: R18.

19. Gurprataap SS, Sebhat E, Heidi P, Aju M (2016) Prevalence of triple breas cancer in India: Systematic review and meta-analysis. J Glob Oncol 2: 412-421.

20. Boyle P (2006) The globalisation of cancer. Lancet 368: 629-630.

21. Easton DF (1999) How many more breast cancer predisposition genes are there? Breast Cancer Res 1: 14-17.

22. Palmieri C, Krell J, James CR, Harper-Wynne C, Misra V, et al. (2010) Rechallenging with anthracyclines and taxanes in metastatic breast cancer. Nat Rev Clin Oncol 7: 561-574.

23. Longley DB, Johnston PG (2005) Molecular mechanisms of drug resistance. J Pathol 205: 275-292.

24. O'Driscoll L, Clynes M (2006) Biomarkers and multiple drug resistance in breast cancer. Curr Cancer Drug Targets 6: 365-384

25. Jssem J, Carroll C, Ward SE, Simpson E, Hind D, et al. (2009) The clinical efficacy of cytotoxic agents in locally advanced or metastatic breast cancer patients pretreated with an anthracycline and a taxane: a systematic review. Eur J Cancer 45: 2749-2758.

26. Jones A, O'Brien M, Sommer H, Nowara E, Welt A, et al. (2010) Phase II study of oral vinorelbine in combination with capecitabine as second line chemotherapy in metastatic breast cancer patients previously treated with anthracyclines and taxanes. Cancer Chemother Pharmacol 65: 755-763.

27. O'Shaughnessy J, Miles D, Vukelja S, Moiseyenko V, Ayoub JP, et al. (2002) Superior survival with capecitabine plus docetaxel combination therapy in anthracycline-pretreated patients with advanced breast cancer: phase III trial results. J Clin Oncol 20: 2812-2823.

28. Rivera E, Lee J, Davies A (2008) Clinical development of ixabepilone and othe epothilones in patients with advanced solid tumors. Oncologist 13: 1207-1223.

29. Cardoso F, Bedard PL, Winer EP, Pagani O, Senkus-Konefka E, et al (2009) International guidelines for management of metastatic breast cancer: combination vs sequential single-agent chemotherapy. J Natl Cancer Inst 101 1174-1181.

30. Chacon RD, Costanzo MV (2010) Triple-negative breast cancer. Breast Cancer Res 12: S3.

31. Foulkes WD, Smith I, Reis-Filho J (2010) Triple-negative breast cancer. N Eng J Med 363: 1938-1948.

32. Gronwald J, Byrski T, Huzarski T, Dent RA, Zuziak D, et al. (2009) Neoadjuvan therapy with cisplatin in BRCA1-positive breast cancer patients. Hered Cance Clin Pract 9: A4.

33. Thomas ES, Gomez HL, Li RK, Chung HC, Fein LE, et al. (2007) Ixabepilone plus capecitabine for metastatic breast cancer progressing after anthracycline and taxane treatment. J Clin Oncol 25: 5210-5217.

34. Miller K, Wang M, Gralow J, Dickler M, Cobleigh M, et al. (2007) Paclitaxel plus bevacizumab versus paclitaxel alone for metastatic breast cancer. $\mathrm{N}$ Engl J Med 357: 2666-2676.

35. Robert NJ, Diéras V, Glaspy J, Brufsky AM, Bondarenko I, et al. (2011) RIBBON-1: Randomized, double-blind, placebo-controlled, phase III trial of chemotherapy with or without bevacizumab for first-line treatment of human epidermal growth factor receptor 2-negative, locally recurrent or metastatic breast cancer. J Clin Oncol 29: 1252-1260.

36. Brufsky A, Valero V, Tiangco B, Dakhil SR, Bousfoul N, et al. (2011) Impact of bevacizumab (BEV) on efficacy of second-line chemotherapy (CT) for triplenegative breast cancer (TNBC): Analysis of RIBBON-2. J Clin Oncol 29.

37. Burstein HJ, Elias AD, Rugo HS, Cobleigh MA, Wolff AC, et al. (2008) Phase II study of sunitinib malate, an oral multitargeted tyrosine kinase inhibitor, in patients with metastatic breast cancer previously treated with an anthracycline and a taxane. J Clin Oncol 26: 1810-1816. 